\title{
Translation of Allusions in Subtitling from English into Persian
}

\author{
Afsaneh Salehi \\ Allameh Tabataba'i University, Tehran, Iran
}

Received: 20-03- 2013

Accepted: 26-04- 2013

Published: 30-04- 2013

doi:10.7575/aiac.ijclts.v.1n.1p.17

URL: http://dx.doi.org/10.7575/aiac.ijclts.v.1n.1p.17

\begin{abstract}
Allusion as a culture-specific item can pose significant problems to translation. Therefore, the intercultural communication is affected by the way it is translated. This study explores the translation of allusions in subtitling from English into Persian. It can help the translators to know how to translate allusions intelligibly and to maintain the functions and connotations of allusions in translation as much as possible. This is a descriptive study which is conducted within the framework of intertextuality to find the most frequently used translation strategy/strategies of allusions and their change of functions, if any, on macro- and micro-level in Persian subtitles. The data include the allusions on verbal auditory and verbal visual channel collected from four films. This study indicates that the most frequently used translation strategies of allusions are 'minimum change' and 'to keep the name unaltered'. Moreover, the current study shows that in most cases functions of allusions weaken or change on macro- and micro-level in translation.
\end{abstract}

Keywords: Audiovisual translation, subtitling, allusion, proper name allusion, key phrase allusion, intertextuality, translation strategy

\section{Introduction}

The problem for translators is to render intertextual references into the target language and culture such that the meanings invoked in the ST are preserved and made accessible to the maximum extent possible. Allusion as an intertextual reference and a type of culture-bound element is a translation problem which requires problem-solving and the use of appropriate translation strategies. According to Irwin (2002:521) allusion is "a reference which is indirect in the sense that it calls for associations which go beyond mere substitution of a referent. Allusions typically draw on information not readily available to every member of a cultural and linguistic community, are typically but not necessarily brief, and may or may not be literary in nature".

In film as well as other non-fictional writings we can find allusions which make the film difficult to understand especially for those non-natives who are not familiar with the source culture. So, one of the problematic issues in this field is how to translate allusions in Persian subtitles in order to make them intelligible for the target audience. Pedersen (2005) regards allusion as culture-bound and a translation crisis point which presents translation problems.

Since allusions may be translated in different ways, their functions may change in Persian subtitles. Burr (2003:10) believes that "allusions may function as instances of the intertextuality that is expected in the genre and that enrich and intensify the viewer's involvement in the text". According to Thomas (1986, cited in Bamman \& Crane, 2008:1) allusions have two main functions: "to express similarity between two passages, so that the latter can be interpreted in light of the former; and to simultaneously express their dissimilarity as well, in that the tradition they recall is revisited". Leppihalme (1997) introduces the functions of allusions as Creative and stereotyped.In particular, this study aims to find how translators deal with allusive material in film subtitles to make other translators aware of allusions and their resulting problems in translation. Analyzing the functions of allusions helps the translators to pay much more attention to functions of allusions in films and prevent the probable functional changes that might occur in translation. This paper focuses on the translation of allusions in film subtitles and aims to answer the following questions: 1. Which strategy/strategies are frequently used in translation of allusions in Persian subtitles? 2. Do functions of allusions change on macro-level and micro-level in Persian (translated) subtitles?

As Kristeva (1969) notes, a text is constructed as a mosaic of quotations, and any text is the absorption and transformation of another. Intertextuality affirms that texts cannot exist or function in isolation from other texts. Allusions are explicit verbal connotations between a text and its intertext(s). Gale (2000) points out that the identification of allusion is part of a broader process of intertextual interpretation and the reader activates these allusions by identifying and interpreting intertextual resemblances. If we want to examine a film's intertextuality we should try to look at the other and prior texts that influenced the film. The explicit and implicit references within a film to another suggest another dimension to the film. Regarding allusion as a device for the simultaneous activation of two texts, our focus on translation of allusions within the framework of intertextuality (Kristeva, 1969) gives us a clue to find out the effects of using the translation strategies on their functions on text micro and macro-level. According to Gennette 
(1992:8, cited in Salo-Oja, 2004:13), "allusion is named as one type of intertextuality along with plagiarism and quotation".

In Iran, dubbing is the preferred mode of audiovisual translation by authorized companies. It has a long history; however, young people have recently favored subtitled films, and universities have begun to include it as a subject for study in their curricula. Subtitling is the focus of several academic conferences every year (Ghaemi\&Benyamin, 2010) and the films are mostly subtitled by unauthorized companies or individuals in Iran. The films selected for this study are from both the authorized and unauthorized companies.

This area is rarely studied in audiovisual translation in Iran; hence this research aims to open up the field, as well as being directly applicable to translation training.

\section{Methodology}

\subsection{Methodological Design of the Study}

This research is a quantitative analysis of translation strategies of allusions based on Leppihalme's (1997) classification; and their functions were analyzed qualitatively based again on Leppihalme. All meaningful stretches of language which were considered allusive were investigated. We followed Leppihalme (1997) in identifying potential allusions. These include, among others, the length of the phrase, non-standard spelling and syntax, deviations in style, rhythm and rhyme, and overt phrases such as 'they say'. Moreover, a number of proper nouns and other phrases were considered allusive and checked surfing through the internet.

\subsection{Corpus}

The corpus selected for this research with a total running time of 490 minutes was a bilingual parallel corpus from 4 films, chosen because they were full of allusions and references to other films and texts.

Table 2.1. The Films Selected for the Study

\begin{tabular}{|c|c|c|c|c|}
\hline Film & Kill Bill Vol 1 & Kill Bill Vol 2 & $\begin{array}{c}\text { O Brother, Where } \\
\text { Art Thou? }\end{array}$ & Pulp Fiction \\
\hline Director & $\begin{array}{l}\text { Quentine } \\
\text { Tarantino }\end{array}$ & $\begin{array}{l}\text { Quentine } \\
\text { Tarantino }\end{array}$ & $\begin{array}{l}\text { Joel and Ethan } \\
\text { Coen }\end{array}$ & $\begin{array}{l}\text { Quentine } \\
\text { Tarantino }\end{array}$ \\
\hline Genre & Action & Action & Drama & Drama \\
\hline Release Date & 2003 & 2004 & 2000 & 1994 \\
\hline Country & United States & United States & United States & United States \\
\hline Running Time & 95 minutes & 137 minutes & 98 minutes & 160 minutes \\
\hline Language & English & English & English & English \\
\hline $\begin{array}{l}\text { Subtitling } \\
\text { Company }\end{array}$ & $\begin{array}{c}\text { Moæsese } \\
\text { dzævaneh puja }\end{array}$ & $\begin{array}{l}\text { Underground } \\
\text { Company }\end{array}$ & $\begin{array}{l}\text { Moæsese } \\
\text { ræsanehaje } \\
\text { Tæsviri }\end{array}$ & $\begin{array}{c}\text { Underground } \\
\text { Company }\end{array}$ \\
\hline
\end{tabular}

\subsection{Method of Data Collection}

All the English film scripts were downloaded from the internet. The meaningful units which were considered as allusive were marked in the original and the Persian subtitles of these allusive units were extracted from the films. According to Leppihalme's (1997) classification of types of allusions, the allusions were classified as proper name (PN) allusions, key phrase (KP) allusions, semi-allusive comparisons (SACs) and stereotyped allusions (allusions in frequent use that have lost their freshness and do not necessarily evoke their sources). Allusions on the verbal-visual channel were found as well. In this study, the references to the names of people (real-life and fictional), places, films, shows, songs, cartoons, fictional works, organizations and groups were classified as proper name allusions. Some allusions repeated in the original were included in the data only once, unless they were translated differently.

\subsection{Method of Data Analysis and Interpretation}

The allusions collected as described above were differentiated according to type and channel, following Leppihalme's (1997) classification of the translation strategies of allusions:

Translation Strategies for PN Allusions:

1)Retention of name:

(1a) use the name as such;

(1b) use the name, adding some guidance;

(1c) use the name, adding a detailed explanation, for example a footnote. 
2) Replacement of name by another:

(2a) replace the name by another SL name;

(2b) replace the name by a TL name.

3) Omission of name:

(3a) omit the name but transfer the sense;

(3b) omit the name and the allusion altogether.

Translation Strategies for KP Allusions:

1) Use of a standard translation,

2) Minimum change, that is, a literal translation,

3) Extra-allusive guidance added in the text,

4) The use of footnotes, endnotes, translator's prefaces and other explicit explanations not slipped in the text but overtly given as additional information,

5) Simulated familiarity or internal marking, that is, the addition of intra-allusive allusion-signaling features (marked wording or syntax),

6) Replacement by a preformed TL item,

7) Reduction of the allusion to sense by rephrasing,

8) Re-creation, using a fusion of techniques: creative construction of a passage which hints at the connotations of the allusion or other special effects created by it,

9) Omission of the allusion.

There were some proper names in the corpus which were regarded as semi-allusive comparisons (SACs). They were analyzed as if they were full PN allusions. The translation strategies of stereotyped allusions were analyzed following KP allusions; while a strategy named 'Other' was introduced for both PN and KP allusions which were translated using strategies not accounted for by Leppihalme.

The 'creative functions' of verbal allusions were analyzed on the macro- and micro-level in the original and translated texts based on Leppihalme's (1997) classification of functions of allusions to see whether there was any change of function or not. The functions were identified by analyzing the main themes of the films; the allusions which contributed to these themes on the macro-level; the allusions which brought humor to the text on the micro-level, and the allusions which described the characters and displayed the relationships between them:

1) Creative functions: thematic importance on the macro-level; parody, irony and other humor (mainly on the micro-level); the use of allusions for characterization; and allusions as indicators of interpersonal relationships in fiction.

2) Stereotyped use of allusions: it includes clichés and proverbs as well as (to use Leppihalme's terms) 'dead' and 'dying' allusions.

\section{Analysis and Interpretation of Data}

This section analyzes and interprets data about the translation strategies of allusions in the four films.

\subsection{Kill Bill Vol. 1}

Most of the PN allusions in Kill Bill Vol. 1 were kept as such in translation, for example:

ST. This Pasadena homemaker's name is Jeanne Bell. (This refers to Jeanne Bell who played in TNT Jackson.)

TT. Esme in cevazi dzini bel aest.

Literal Translation: This bitch's name is Jeanie Bell.

One SAC was classified as 'other' because the allusion was omitted and meaning is distorted in translation:

ST. The pretty lady to O-Ren Ishii's right who's dressed like she's a villain on 'Star Trek' is O-Ren lawyer. (It refers to the villains in the film Star Trek.)

TT. in zane ziba ke torafe raste oren istade va lebase fazaie pufide, vakile oren cest.

Literal Translation: This pretty woman who is standing to Oren's right and is wearing spacesuit, is Oren's lawyer. 
Table 3.1.1. PN Allusions and SACs in Kill Bill Vol. 1

\begin{tabular}{c|c|c}
\hline Strategy & PN Allusion & SAC \\
\hline $1 \mathrm{a}$ & 7 & $\mathbf{1}$ \\
$1 \mathrm{~b}$ & 0 & $\mathbf{0}$ \\
$1 \mathrm{c}$ & 0 & $\mathbf{0}$ \\
$2 \mathrm{a}$ & 0 & $\mathbf{0}$ \\
$2 \mathrm{~b}$ & 0 & $\mathbf{0}$ \\
$3 \mathrm{a}$ & 0 & $\mathbf{0}$ \\
$3 \mathrm{~b}$ & 0 & $\mathbf{0}$ \\
Other & 0 & $\mathbf{1}$ \\
Total & $\mathbf{7}$ & $\mathbf{2}$ \\
\hline
\end{tabular}

Most of the KP allusions were translated with minimum change (first example) and one of them was omitted (second example) in translation:

ST. Her code name was "Copperhead".

(The same name is given to a member of the bad men group in Captain America.)

TT. Kæle mesi sedajæ $\int$ mikærdænd.

Literal Translation: They used to call her, copperhead.

In this example, the literal translation (head of copper) has lost the reference to the film.

ST. ...Codename Cottonmouth. (A member of the bad men group in Captain America)

TT. - omitted -

The following KP allusion was recreated in translation:

ST. Chapter two: The blood splattered Bride. (It refers to a horror film called The Blood Spattered Bride.)

TT. Qesmæte dovom: ærusie xun.

Literal Translation: Chapter two: blood wedding.

In the following example the KP allusion is reduced to sense by rephrasing. The sentence is not translated literally and the translator prefers to transfer the sense:

ST. If, on your journey, you should encounter god, god will be cut. (This means that not even god will be able to stop your journey. The allusion may have been taken from the film Samurai Reincarnation.)

TT. dzaengdzujane vaqeie hengame mobareze faeqaet be aez bein bordane dofmaen fekr mikonand. Faeqaet zende bemun.

Literal Translation: the real worriers during the fight just think about destroying the enemy. Just survive.

There was one stereotyped allusion (also used in The Godfather) on the verbal-visual channel which was not translated: 


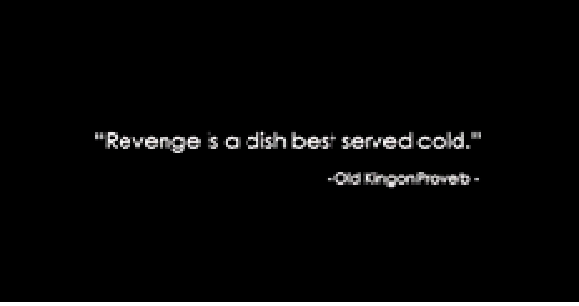

Image 1. The old Klingon Proverb from Star Trek 2: Wrath of Khan (1982) in Kill Bill Vol. 1

Table3.1.2. KP and Stereotyped Allusions in Kill Bill Vol. 1

\begin{tabular}{c|c|c}
\hline Strategy & KP Allusion & $\begin{array}{c}\text { Stereotyped } \\
\text { Allusion }\end{array}$ \\
\hline 1 & 0 & $\mathbf{0}$ \\
2 & 5 & $\mathbf{0}$ \\
3 & 0 & $\mathbf{0}$ \\
4 & 0 & $\mathbf{0}$ \\
5 & 0 & $\mathbf{0}$ \\
6 & 0 & $\mathbf{0}$ \\
7 & 2 & $\mathbf{0}$ \\
8 & 1 & $\mathbf{0}$ \\
9 & 1 & $\mathbf{1}$ \\
Other & 2 & $\mathbf{0}$ \\
Total & $\mathbf{1 1}$ & $\mathbf{1}$ \\
\hline
\end{tabular}

\subsection{Kill Bill Vol. 2}

From the 4 PN allusions in Kill Bill Vol. 2, one allusion was omitted but its sense was transferred. In the following example, the black mamba is translated into black snake:

ST. Budd I like to introduce my friend, the black mamba.

(This also refers to the character, nick-named Black Mamba in Kill Bill Vol. 1.)

\section{TT. bad mixam ke ba dustcem afna befi: "mare siah".}

Literal Translation: Budd I like to introduce my friend: "black snake", whereas the character Black Mamba in Vol. 1 was translated as "Mambaje Siah", "Black Mamba".

The one SAC in Kill Bill Vol.2 was kept as such in translation.

Table 3.2.1. PN Allusions and SACs in Kill Bill Vol. 2

\begin{tabular}{c|c|c}
\hline Strategy & PN Allusion & SAC \\
\hline $1 \mathrm{a}$ & 2 & $\mathbf{1}$ \\
$1 \mathrm{~b}$ & 0 & $\mathbf{0}$ \\
$1 \mathrm{c}$ & 0 & $\mathbf{0}$ \\
$2 \mathrm{a}$ & 0 & $\mathbf{0}$ \\
$2 \mathrm{~b}$ & 0 & $\mathbf{0}$ \\
$3 \mathrm{a}$ & 1 & $\mathbf{0}$ \\
$3 \mathrm{~b}$ & 0 & $\mathbf{0}$ \\
Other & 1 & $\mathbf{0}$ \\
Total & $\mathbf{4}$ & $\mathbf{1}$ \\
\hline
\end{tabular}


In Kill Bill Vol. 2, 2 KP allusions were translated with minimum change:

ST. I'm the deadliest woman in the world. (In Pulp Fiction, Mia says the same.)

\section{TT. Man qahhartarin zoene donja hoestam.}

Literal Translation: I am the deadliest woman in the world.

Table 3.2.2. KP Allusions Kill Bill Vol. 2

\begin{tabular}{c|c}
\hline Strategy & KP Allusion \\
\hline 1 & $\mathbf{0}$ \\
2 & $\mathbf{2}$ \\
3 & $\mathbf{0}$ \\
4 & $\mathbf{0}$ \\
5 & $\mathbf{0}$ \\
6 & $\mathbf{0}$ \\
7 & $\mathbf{0}$ \\
8 & $\mathbf{1}$ \\
9 & $\mathbf{0}$ \\
Other & $\mathbf{0}$ \\
Total & $\mathbf{3}$ \\
\hline
\end{tabular}

\subsection{O' Brother Where Art Thou?}

Most of the PN allusions in O' Brother Where Art Thou? were retained (which includes transliteratation)as in the following example. In only one instance was the allusion omitted in translation:

ST. ... and good pure pappy O'Daniel flour. (W. Lee (Pappy) O'Daniel served as governor of Texas.)

TT. homintor cez arde xalese "papi odaniel".

Literal Translation: .... and also pure "Pappy Odaniel” flour.

Table 3.3.1. PN Allusions and SACs in O’ Brother Where Art Thou?

\begin{tabular}{c|c|c}
\hline Strategy & PN Allusion & SAC \\
\hline 1a & 11 & $\mathbf{1}$ \\
$1 \mathrm{~b}$ & 0 & $\mathbf{0}$ \\
$1 \mathrm{c}$ & 0 & $\mathbf{0}$ \\
$2 \mathrm{a}$ & 0 & $\mathbf{0}$ \\
$2 \mathrm{~b}$ & 0 & $\mathbf{0}$ \\
$3 \mathrm{a}$ & 0 & $\mathbf{0}$ \\
$3 \mathrm{~b}$ & 1 & $\mathbf{0}$ \\
Other & 0 & $\mathbf{0}$ \\
Total & $\mathbf{1 2}$ & $\mathbf{1}$ \\
\hline
\end{tabular}

All of the KP allusions in $O$ ' Brother Where Art Thou? were translated with minimum change except for one allusion which was mistranslated:

ST. and these here are the Soggy Bottom Boys. (It refers to the famous Foggy Mountain Boys band and also is a humorous name given the two backup singers who became wet earlier.)

TT. Ina hoem batfehaje xodsaxteie hoestoen.

Literal Translation: And these are the self-reliant boys. 
Table3.3.2. KP Allusions in O' Brother Where Art Thou?

\begin{tabular}{c|c}
\hline Strategy & KP Allusion \\
\hline 1 & $\mathbf{0}$ \\
2 & $\mathbf{7}$ \\
3 & $\mathbf{0}$ \\
4 & $\mathbf{0}$ \\
5 & $\mathbf{0}$ \\
6 & $\mathbf{0}$ \\
7 & $\mathbf{0}$ \\
8 & $\mathbf{0}$ \\
9 & $\mathbf{0}$ \\
Other & $\mathbf{1}$ \\
Total & $\mathbf{8}$ \\
\hline
\end{tabular}

\subsection{Pulp Fiction}

Most of the PN allusions in Pulp Fiction were retained as such in translation. The PN allusion in the following example is partly omitted:

ST. Douglas Sirk steak, I'll have that. (It refers to the famous film director Douglas Sirk.)

TT. Ahan boeraje moen estejke daglas biar.

Literal Translation: Well I'll have Douglas steak.

8 SACs were used as such in translation and 3 SACs were translated as 'other'. In the following example, the SAC is partially translated into Persian, i.e. 'daddy' is translated into 'Babaie' and the reference to the film is lost:

ST. You can get a steak here, daddy-o. (It refers to the film Daddy-O.)

TT. indza hoem mituni estejk boxori. Babaie.

Literal Translation: You can eat steak here, daddy.

Table 3.4.1. PN Allusions and SACs in Pulp Fiction

\begin{tabular}{c|c|c}
\hline Strategy & PN Allusion & SAC \\
\hline 1a & 15 & $\mathbf{8}$ \\
1b & 0 & $\mathbf{0}$ \\
$1 \mathrm{c}$ & 0 & $\mathbf{0}$ \\
$2 \mathrm{a}$ & 0 & $\mathbf{0}$ \\
2b & 0 & $\mathbf{0}$ \\
$3 \mathrm{a}$ & 0 & $\mathbf{0}$ \\
$3 \mathrm{~b}$ & 0 & $\mathbf{2}$ \\
Other & 2 & $\mathbf{3}$ \\
Total & $\mathbf{1 7}$ & $\mathbf{1 3}$ \\
\hline
\end{tabular}

Most of the KP allusions were translated with minimum change in Pulp Fiction. One KP allusion was reduced to sense in translation:

ST. My name's Paul, and this is between y'all.

(It refers to the same rhyming lines in School Daze.)

\section{TT. bebin in tfizha be man rabti nadare.}

Literal Translation: See these things are none of my business. 
Table 3.4.2. KP Allusions in Pulp Fiction

\begin{tabular}{c|c}
\hline Strategy & KP Allusion \\
\hline 1 & $\mathbf{0}$ \\
2 & $\mathbf{1 7}$ \\
3 & $\mathbf{0}$ \\
4 & $\mathbf{0}$ \\
5 & $\mathbf{0}$ \\
6 & $\mathbf{0}$ \\
7 & $\mathbf{1}$ \\
8 & $\mathbf{0}$ \\
9 & $\mathbf{0}$ \\
Other & $\mathbf{2}$ \\
Total & $\mathbf{2 0}$ \\
\hline
\end{tabular}

\section{Functions of Allusions}

\subsection{Thematic function}

The film O' Brother, Where Art Thou? is based on Homer's Odyssey. The main themes of O' Brother, Where Art Thou? are classical mythology, the great depression era in 1930's in America and American popular culture. It is a comedic reproduction of The Odyssey and displays a reference to the films Sullivan's Travels (1941) and The Wizard of Oz (Carter, 2008).

Some of the thematic allusions which refer to the classical mythology are:

\section{ST. M'name's Ulysses Everett McGill}

(Ulysses is is derived from Ulixes, the Latin name for Odysseus, the hero of The Odyssey).

TT. esme man ulis everet mak gile.

Literal Translation: My name is Ulis Everet Macgill.

ST. Penny, you stop that (Penny is the shortened form of Penelope (Odysseus's wife)).

TT. peni boes kon dige.

Literal Translation: Penny that's enough.

The PN allusions which reinforce the theme were mostly retained in translation and didn't have noticeable change of functions in translation.

Pulp Fiction is a crime drama with a gangster tale and ironic mix of humor and violence. Tarantino goes into the world of crime. For the characters in Pulp Fiction, killing, stealing etc. are cliché. One of the main themes of this film is crime and Blaxploitation (blaxploitation films are with black actors, ostensibly for black audiences, whose subgenre is crime) (Imdb, n. d. ) and some of the allusions contribute to this theme:

\section{ST. Every time my fingers touch brain I'm "Superfly T.N.T".}

\section{TT. haer bar ke aengoftancem be moeqz mixore ti en ti mifcem.}

Literal Translation: Every time my fingers touch brain I become T.N.T.

This is a reference to the crime and blaxploitation film Super Fly T.N.T. (1973). In this film, former drug dealer Youngblood Priest is living in Rome with his lover. His life has become peaceful and he is utterly bored, so when a gun-smuggling African revolutionary shows up, he decides to help him overthrow the tyrant who is running the rebel's 
country (Nytime, n. d.). In Pulp Fiction the title of the film was referred to but it was partly omitted in translation. The translation only shows Jules' anger and the function of this allusion which reinforces the theme of crime has changed.

Kill Bill Vol. 1 and 2 are rooted in 60s/70s grindhouse Cinema (exploitation movies) which usually involves extreme violence, gore and horror (Imdb, n. d.). The following example refers to an exploitation film called Bury Me an Angel which has this tagline: "She's a Howling Hellcat Humping a Hot Steel Hog on a Roaring Rampage of Revenge!" (Imdb, n. d.):

\section{ST. I went on what the movie advertisements refer to as "a Roaring Rampage of Revenge".}

\section{TT. be donbale enteqam budcem, be qole filmsazha: "nce 're fire zian baraje enteqam”.}

Literal Translation: I was seeking revenge, as filmmakers say: "the roar of the furious lion for revenge".

The translator tried to be creative and freed himself from the limitations of ST. There was a slight change in meaning but the translation contributed to the thematic function of the allusion to some extent.

\subsection{The Function of Allusions for Humor}

One of the problems in enjoying a comedy from a different culture is that the reader/viewer might not get the allusions, and ends up missing a great deal of the humor.

An example of allusion used for humor on micro-level in Kill Bill Vol. 1 is:

\section{ST. O-Ren: Silly rabbit}

O-Ren/Bride: Trix are for kids.

\section{TT. xargufe mazlum}

va unha gorg hoestoend.

Literal Translation. O-Ren: Poor rabbit. O-Ren/Bride: And they are wolves.

The allusion refers to an advertising slogan for breakfast cereal (Trix) in which a rabbit is a cartoon mascot (The Iranian audience is not familiar with this advertisement). That was something O-ren and the Bride used to say to each other when they were Deadly Vipers and they both said it at the same time in an amusing way in this scene. It was a private joke between the two of them. Tarantino leaves the mystery of the line unsolved without further explanation. It is also a cryptic reference to The Bride's name, which in Kill Bill Vol. 2 is revealed to be Beatrix Kiddo. Both allusions are lost.

As another example, in Pulp Fiction, Jules calls Roger "Flock of Seagulls" because of his haircut. It is a trademark of the 80 's new wave band which is mistranslated as morqabi. (duck). There is no reference to the band in translation, and hence the humorous allusion to the lead singer Mike Score's distinct haircut is lost.

\subsection{The Function of Allusions for Characterization}

Here, we analyze some of the allusions used for characterization in the 2 Kill Bill 's, including the allusions other characters used to describe The Bride and the allusions The Bride herself made use of, are analyzed. These all occur at the macro-level.

In Kill Bill Vol. 1 and Vol. 2, the story centers on The Bride, a former professional assassin. She is depicted as a super hero who seeks revenge. In Kill Bill Vol. 1 she says (referring to herself): “...she made one big mistake...She should have killed ten". The allusion is translated as: un jek eftebahe bozorg mortakeb fod un bajaed daeh naefar ro mikoft. (She made a big mistake she should have killed ten people). It refers to the similar line in Death Rides a Horse (1969). The translation follows the original text closely but the allusion itself remains unclear. The key phrase allusions are hardly recognized in translation by the Persian viewers because most of them are translated literally without any guidance.

In Kill Bill Vol. 2, Budd as one of the former members of DiVAS (Deadly Viper Assassination Squad) refers to The Bride in this way:

ST. I never saw anybody buffalo Bill the way she buffaloed Bill. 


\section{TT. hitf doxtceri ro noedidaem ke cendaze un ede 'aje mardi bokone.}

Literal Translation: I've never seen a girl like her claim to be so macho.

The original allusion refers to William Fredrick 'Buffalo Bill' Cody (1846-1917) who was an American soldier, hunter and showman. The translator has misunderstood and mistranslated the allusion. The allusion included an amusing play on words (a reference to Buffalo Bill and also to Bill), which was omitted in translation. "Macho" is clearly a misinterpretation, as the Bride is characterized here as a woman who has deceived or tricked Bill. Also, Budd continues: "Bill used to think that she was smart. I tried to tell him she is just smart for a blonde".

\subsection{Allusions as Indicator of Interpersonal Relationships}

Some of the allusions extracted from the corpus displayed the interpersonal relationships between the two characters in different ways. For example, in a scene in Pulp Fiction, Jules tells Vincent that he is going to walk the earth. It was an allusion to the American TV series Kung Fu (1972-1975). Vincent doesn't get the allusion and asks for more explanation which shows his inferiority and Jules' superior knowledge and intelligence:

ST. Jules: First, I'm gonna deliver this case to Marsellus. Then, basically, I'm just gonna walk the earth.

Vincent: What do you mean, walk the earth?

Jules: You know, like Caine in "Kung Fu”.

TT. Jules: avael in kif ro miresunam be marselus ba'd xejli sade koreje zamin ro mipejmajam.

Vincent: monzuret tfie kore zamin ro mipejmajee?

Jules: mesle kejn daer kong fu.

Literal Translation: First I deliver this case to Marsellus then very easily I'm gonna walk the earth.

Vincent: What do you mean walk the earth?

Jules: Like Caine in "Kung Fu".

Jules alludes to the name of the character and the TV series to clarify what he means by 'walk the earth'. The allusion was clear in translation as Kung Fu is popular in Iran and 'I'm gonna walk the earth' is translated the same; its function didn't change.

In another dialogue in Pulp Fiction, Jules alludes to Fonzie who is the famous star in the American sitcom Happy Days (1974-1984) and his famous line 'correct-amundo':

ST. Jules: Nobody's gonna hurt anybody. We're gonna be like three Fonzies. And what' Fonzie like? C'mon Yolanda, what's Fonzie like?

Yolanda: He's cool?

Jules: Correct-amundo! And that's what we're gonna be, we're gonna be cool.

TT. kcesi kasi ro cezijœet nemikone!hømcemun mesle seta fonzi mifinim. fonzi tfetorie? begu julanda! fonzi tfetorie? arume?

doroste va in tfizie ke ma xahim bud. ma arum xahim bud.

Literal Translation: Jules: Nobody's gonna hurt anybody! We're gonna be sitting down like three Fonzies. What' Fonzie like? C'mon Yolanda! what's Fonzie like?

Yolanda: He's cool?

Jules: Correct and that's what we are gonna be. We are gonna be cool.

There is no answer to Jules' first question but when he repeats the question Yolanda answers it as 'He is cool?'. She is unsure about the answer (mentioned in the film script). After a few seconds she catches the allusion. 'Fonzie' is retained in translation as such (transliterated) and its function didn't change. Jules confirms Yolanda's reply by alluding to 
Fonzie's famous line. Here, the sense of the allusion is transferred but its function (showing the superiority of Jules and his knowledge) is not clear in translation.

\section{Findings and Discussion}

By analyzing the corpus, 100 verbal allusions (including the allusions on verbal auditory and verbal visual channel) were found, including 40 proper name allusions, 17 semi-allusive comparisons, 42 key phrase allusions and 1 stereotyped allusion.

This research found answers to the following questions:

1. Which strategy/strategies are frequently used in translation of allusions in Persian subtitles?

2. Do functions of allusions change on macro-level and micro-level in Persian (translated) subtitles?

To answer the first question, the analysis and the percentage of the translation strategies of allusions in the corpus are displayed:

Table 5.1. Translation Strategies

for PN Allusions and SACs in the Corpus

\begin{tabular}{c|c|c}
\hline Strategy & PN Allusion & SAC \\
\hline $1 \mathrm{a}$ & 35 & $\mathbf{1 1}$ \\
$1 \mathrm{~b}$ & 0 & $\mathbf{0}$ \\
$1 \mathrm{c}$ & 0 & $\mathbf{0}$ \\
$2 \mathrm{a}$ & 0 & $\mathbf{0}$ \\
$2 \mathrm{~b}$ & 0 & $\mathbf{0}$ \\
$3 \mathrm{a}$ & 1 & $\mathbf{0}$ \\
$3 \mathrm{~b}$ & 1 & $\mathbf{2}$ \\
Other & 3 & $\mathbf{4}$ \\
Total & $\mathbf{4 0}$ & $\mathbf{1 7}$ \\
\hline
\end{tabular}

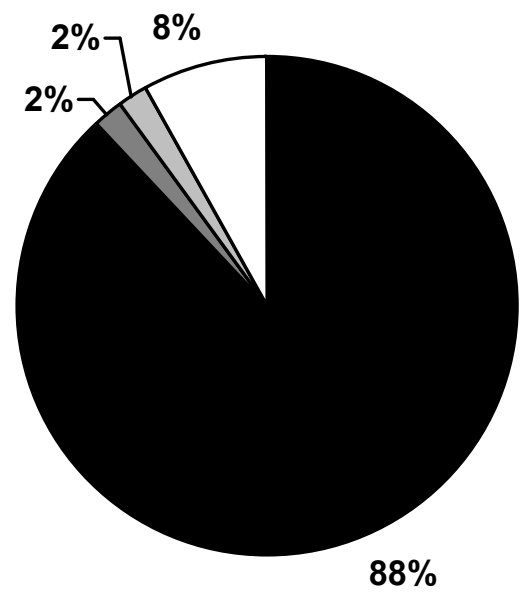

Use the Name as Such

$\square$ Omission of Name and Allusion

$\square$ Omission of Name but Transfer Sense

$\square$ Other

Figure 5.1. Translation Strategies for PN Allusions in the Corpus 


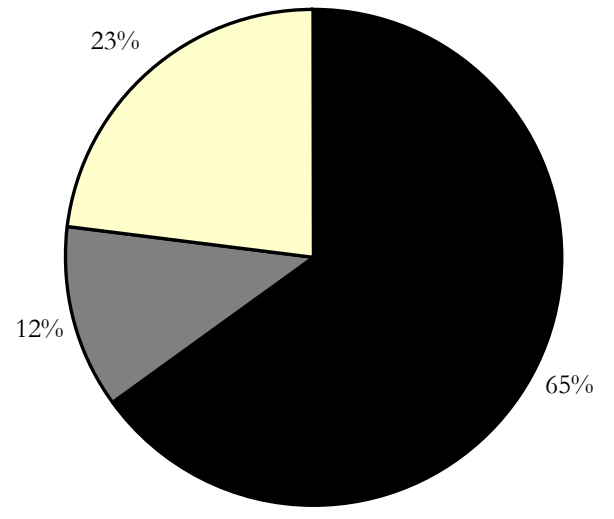

Use the Name as Such

$\square$ Omission of Name and Allusion

$\square$ Other

Figure 5.2. Translation Strategies for SACs in the Corpus

Table 5.2. Translation Strategies

for KP and Stereotyped Allusions in the Corpus

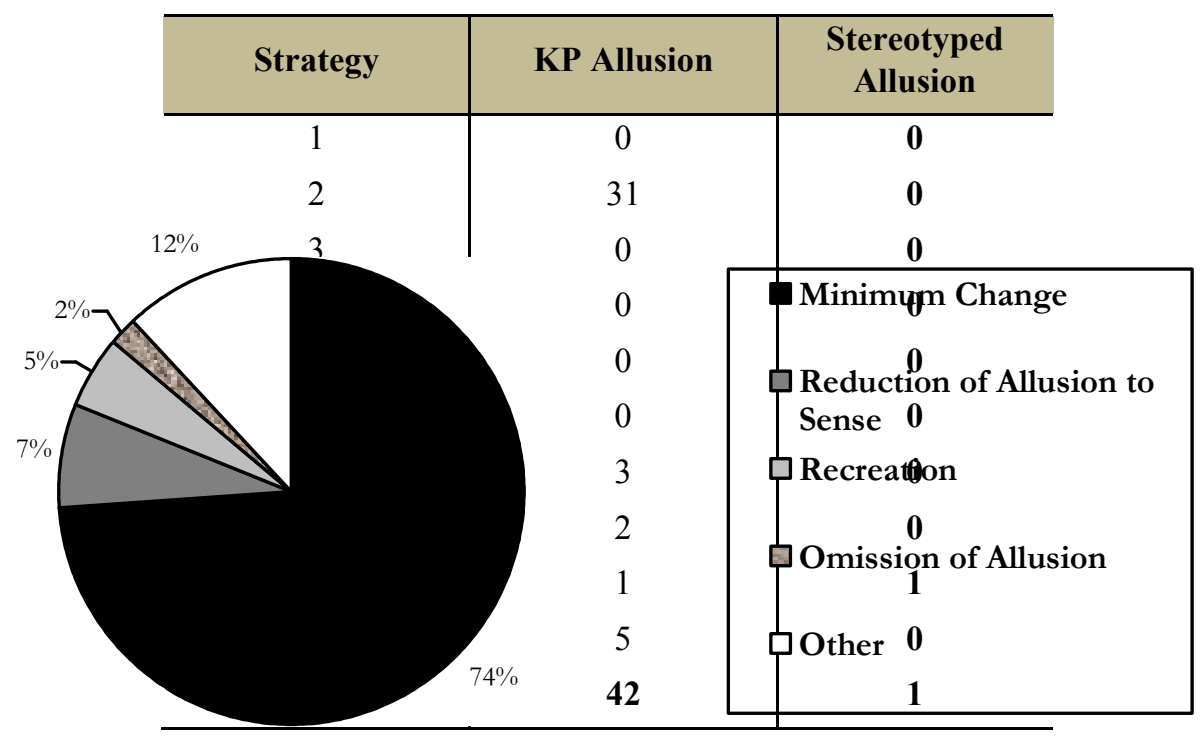

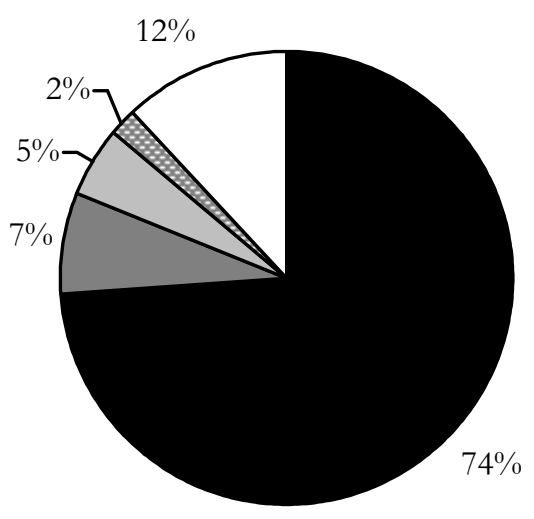

Minimum Change

Reduction of Allusion to Sense

$\square$ Recreation

움 Omission of Allusion

$\square$ Other

Figure 5.3. Translation Strategies for KP Allusions in the Corpus 
As we can see, most of the PN allusions $(88 \%)$ and two-thirds of the SACs $(65 \%)$ were retained as such. Also threequarters (74\%) of the KP allusions were translated with minimum change. The only stereotyped allusion was omitted in translation. So, the most frequently used translation strategies of allusions were 'to keep the name unaltered' and 'minimum change'.

The spatial and temporal constraints of subtitling were probably the main reasons for translators' preferences of the translation strategies of 'minimum change' and 'to keep the name unaltered'. The translators only occasionally used 'reduction to sense by rephrasing'. The translational preference of minimum change strategy may imply that the translators have translated with minimum effort to convey the allusions in translation. Perhaps the translators felt that the additional guidance or the details do not add anything of relevance to the text or possibly the viewers were expected to recognize the allusions and the connotations they bring to the text.

These preferred strategies of minimum change and retention of the name as such may make it challenging for the viewers to understand the connotations of the allusions in the films. Esko Hellgren conducted a similar research on the translation strategies of allusions in the animated cartoon The Simpsons in 2007. In this study, the specific challenges and opportunities that subtitling presents were defined. Similarly, Hellgren found that the translator favored keeping proper name allusions as unchanged as possible and only chose another strategy when the connotations of the name were likely to be obscure to the target audience, or subtitling space did not allow her to provide a translation. However, unlike the KP allusions in the current study, they were translated in a more varied way in The Simpsons, without clearly preferring any one strategy.

This study shows that the translation strategies used by the translators affected mainly the KP functions. The PN allusions were mostly kept unchanged in translation and those familiar with the intertextual references could understand the referents and connotations. In the original, some of the allusions reinforced the theme or had considerable effect on the text on a macro-level. The other allusions were local-level devices and occurred on a micro-level. In about 12 percent of the cases, the translators partially omitted the allusions or mistranslated them. They were not probably familiar with the source culture and the intertextual markers, and hence there were some misunderstandings by the translators. Salo-Oja (2004) in a similar study on two of Reginald Hill's detective novels, looked at the translation of allusions and their functions and found that the translators' choices of strategy probably resulted in slight changes in texts, in muting of themes and in failures to support the characterization present in the source texts.

\section{Summary, Conclusion and Suggestions}

In this research, the translators' preferred strategies of 'minimum change' and 'to keep the name unaltered' proved that they were not willing to depart from the original, mainly because they probably wanted to be faithful to the original. Another reason can be the spatial constraint of subtitling. The functions of some of the allusions were weakened in translation because there was no additional guidance to contribute to the significances of these allusions in the text. The translator chose literal translation but s/he could at least add the name of the film, character, the book etc. that the allusion was derived from (regarding the space limit) as guidance to the translation. Some loss in translating allusions is inevitable, even in the literal translation. In this study, the translation losses occurred specially when the translators mistranslated or omitted the allusions partially or completely (overall, 17\%) and these losses affected the functions.

This study can contribute to translation training and make the translation teachers and students conscious about the allusions as the intertextual elements, and the complicated three-step process of translating allusion(to recognize the allusion, to understand the allusive meaning and to convey the force of the allusion in the TT) specially in films. Through discussing the translation strategies, the translators will learn that if they translate a film without recognizing and understanding its allusions, their translation doesn't have the intended effect on the TT viewers and the meanings of allusive terms will be lost for most of them. As has been seen, a literal translation does not ensure understanding of the allusion.

Additional studies need to be carried out on the impact of genre on allusions and their translation into Persian. The same research should be done in dubbing compared to subtitling to find the differences in translation strategies of allusions. Moreover, the viewers' or readers' perception of the translated allusions and the functional changes of allusions in translation from their viewpoints should be explored.

\section{Acknowledgments}

I am very thankful to Dr. R. Leppihalme for her prompt answers and her comments. I acknowledge my gratitude to Dr. W. Irwin for sending me his articles and consideration.

\section{References}

Bamman, D. \& Crane, G. (2008). The Logic and Discovery of Textual Allusion. Retrieved 25/8/2008 from: http://www.perseus.tufts.edu/ ababeu/latech2008.pdf

Burr, V. (2003). It all seems so real: Intertextuality in the Buffyverse. Refractory: a Journal of Entertainment Media, vol. 2. Retrieved 10/11/2007 from: http://blogs.arts.unimelb.edu.au/refractory/2003/03/18/it-all-seems-so-realintertextuality-in-the-buffyverse-vivien-burr/Carter, S. (2008). O Brother Where Art Thou? Retrieved 9/11/2008 from: http://westga.edu/ scarter/OBrother.htmGale, M. R. (2000). Virgil on the Nature of Things: The Georgics, Lucretius, 
and the Didactic Tradition. Cambridge: Cambridge University Press. Retrieved 7/11/2008 from: http://assets.cambridge.org/97805217/81114/excerpt/9780521781114_excerpt.pdf

Ghaemi, F \& Benyamin, J (2010). Strategies Used in Translation of Interlingual Subtitling. IU Journal of Translation Studies. Retrieved 5/8/2012 from:

http://journals.istanbul.edu.tr/tr/index.php/ceviri/article/.../9250/8597

Hellgren, E. (2007). Translation of Allusions in the Animated Cartoon the Simpsons. Thesis. University of Helsinki. Retrieved 10/12/2007 from: http:// snpp.com/other/papers/eh.paper.pdf

Irwin, W. (2002). The Aesthetics of Allusion. The Journal of Value Inquiry, 36: 521-532.

Kristeva, J. (1969). Desire in Language: A Semiotic Approach to Literature and Art. Oxford: Blackwell.

Leppihalme, R. (1997). Culture Bumps: An empirical approach to the translation of allusions. Clevedon: Multilingual Matters.

Nytime. (n. d.). Superfly T.N.T. Retrieved 22/8/2008 from:

http://movies.nytimes.com/movie/47860/Super-Fly-T-N-T-/overview

Pedersen, J. (2005). How is Culture Rendered in Subtitles? Challenges of Multidimensional Translation: Conference Proceedings. Retrieved 10/11/2008 from:

http://www.euroconferences.info/proceedings/2005 Proceddings/2005 Pedersen Jan.pdf

Salo-Oja, M. (2004). Lost in translation? Translating allusions in two of Reginald Hill's Dalziel \& Pascoe novels. Thesis. University of Helsinki. Retrieved 10/12/2007 from: https://oa.doria.fi/bitstream/handle/10024/840/lostintr.pdf

The Internet Movie Script Database. (n. d.). Kill Bill. Retrieved 25/9/2008 from:

http://imdb.com/title/tt0266697/trivia

The Internet Movie Database. (n. d.). Kill Bill Vol 2. Retrieved 25/9/2008 from:

http://imdb.com/title/tt0378194/movieconnectionsThe Internet Movie Script Database. (n. d.). Pulp Fiction. Retrieved 25/9/2008 from:http:/www.imdb.com/title/tt0110912/

Toury, G. (1995). Descriptive Translation Studies - And Beyond. Amsterdam and Philadelphia, PA: John Benjamins. 